\title{
Etoposide induces growth arrest and disrupts androgen receptor signaling in prostate cancer cells
}

\author{
SHICHENG LIU and HITOSHI YAMAUCHI \\ Department of Research and Development, Nipro Patch Co., Ltd., \\ 8-1, Minamisakae-cho, Kasukabe, Saitama 344-0057, Japan
}

Received August 19, 2009; Accepted September 28, 2009

DOI: $10.3892 /$ or_00000618

\begin{abstract}
Androgen and androgen receptor (AR)-mediated signaling are crucial for the development of prostate cancer. The present study indicates that the topoisomerase II inhibitor etoposide strikingly inhibits androgen/AR-mediated cell growth and androgen-stimulated DNA synthesis in prostate cancer cells. Etoposide significantly repressed the AR mRNA and protein expression in a dose-dependent manner. Etoposidemediated down-regulation of AR was associated with blocking androgen-induced AR translocation from cytoplasm into nucleus of cells. Additionally, etoposide disrupted the association of AR and heat shock protein 90 and impeded binding of the synthetic androgen $\left[{ }^{3} \mathrm{H}\right] \mathrm{R} 1881$ to AR in LNCaP cells. Etoposide simultaneously reduced the intracellular and secreted PSA levels, a marker for the progression of prostate cancer. These findings collectively reveal that etoposide not only serves as a traditional genotoxic agent but directly targets $\mathrm{AR}$ as an AR disrupting therapeutic strategy in prostate cancer.
\end{abstract}

\section{Introduction}

It is widely accepted that androgen plays an important role in both the development and maintenance of the normal prostate, as well as in the initiation and progression of prostate cancer. The androgen receptor (AR) has been studied extensively since the cloning of its cDNA structure in 1988 (1), to elucidate its biological role in the development and progression of prostate cancer. Overexpression of the AR signaling pathway may be linked to the progression of prostate cancer (2). AR belongs to the nuclear steroid hormone receptor superfamily and is the essential mediator for androgen action. It is complexed in the cytoplasm to chaperone proteins that keep the receptor in a transcriptionally inactive form. Upon binding of the native ligand, DHT, AR dissociates from the chaperone and rapidly translocates into the nucleus where it binds to androgen response elements (AREs) and activates target genes such as

Correspondence to: Dr Shicheng Liu, Department of Research and Development, Nipro Patch Co., Ltd., 8-1, Minamisakae-cho, Kasukabe, Saitama 344-0057, Japan

E-mail: liu@nipro-patch.co.jp

Key words: etoposide, prostate cancer, androgen receptor, prostatespecific antigen prostate-specific antigen (PSA) gene $(3,4)$. PSA belongs to an androgen-regulated kallikrien-like serine protease produced by both prostate epithelial cells and prostate cancer and is the most commonly used serum marker for the diagnosis and progression of prostate cancer. PSA gene expression is regulated by androgen through several well-characterized AREs to which the AR binds to initiate transcription (5).

The topoisomerase II inhibitor etoposide is one of several podophyllotoxin derivatives that has been widely used as an anti-tumor drug by coupling DNA damage to apoptosis (6). Topoisomerase II is a nuclear enzyme that functions during both DNA replication and transcription. It prevents 'knots' from forming in DNA by allowing the passage of an intact segment of the helical DNA through a transient double strand break (7). The topoisomerase II inhibitor such as etoposide stabilize the complex formed by topoisomerase II and 5'cleaved ends of the DNA, thus forming stable protein-linked DNA double strand breaks. Cells are apparently able to recognize such DNA damage and, in turn, to eliminate the injured cells by apoptosis (8). Substantial literature details many specific biochemical events that occur upon induction by etoposide in a variety of cell types of apoptotic cascade. However, the molecular mechanisms responsible for the AR signaling pathway of this compound are poorly understood and the potential benefits of etoposide for the treatment of prostate cancer have not received enough attention.

To gain greater insight into the mechanism of etoposidemediated growth inhibition of prostate cancer, we used LNCaP and PC-3 cell lines for the following purposes: i) to investigate cellular cytotoxicity; ii) to determine the protein level of AR and its cellular distribution; and iii) to clarify the molecular mechanism of AR signaling pathway in response to etoposide in prostate cancer cells.

\section{Materials and methods}

Materials. Fetal bovine serum and tissue culture media were obtained from Invitrogen (Grand Island, NY). The cell proliferation kit (XTT) and CytElisa ${ }^{\mathrm{TM}}$ Human PSA kit were obtained from Roche Diagnostics (Mannheim, Germany) and Cytimmune Science (Rockville, MD). Anti-AR, Hsp90 and PSA antibodies were purchased from Santa Cruz Biotechnology (Santa Cruz, CA). 17AAG was obtained from Assay Designs. Etoposide, cyproterone acetate (CPA) and anti- $\beta$-actin antibody were obtained from Sigma Chemical Co. (St. Louis, MO). R1881 was obtained from Daiichi Pure Chemicals 
(Japan), $\left[{ }^{3} \mathrm{H}\right] \mathrm{R} 1881$ and $\left[{ }^{3} \mathrm{H}\right]$ thymidine were obtained from NEN Life Science Products (Boston, MA).

Cell culture and XTT assay. LNCaP and PC-3 cells were obtained from the American Type Culture Collection and cultured routinely in 96-well culture plates at $5 \times 10^{3}$ cells/well in phenol red-free RPMI-1640 containing 5\% normal FBS or dextran-charcoal-stripped FBS (CSS) with or without $1 \mathrm{nM}$ $\mathrm{R} 1881$. After treatment with etoposide at different concentrations for $48 \mathrm{~h}, 50 \mu \mathrm{l}$ of XTT labeling mixture was added to each well and the cells were incubated for an additional $6 \mathrm{~h}$. The absorbance was measured at $450 \mathrm{~nm}$ with a reference wavelength of $650 \mathrm{~nm}$ on a 96 -well microplate reader.

$\left[{ }^{3} H\right]$ Thymidine incorporation. Cells were grown in 96-well plates at $5 \times 10^{3}$ cells/well in phenol red-free RPMI-1640 containing $5 \%$ normal FBS or CSS with or without $1 \mathrm{nM}$ R1881. After the treatment with etoposide at different concentrations for $24 \mathrm{~h}$, the cells were pulsed with $1 \mu \mathrm{Ci} /$ well of $\left[{ }^{3} \mathrm{H}\right]$ thymidine for $4 \mathrm{~h}$ at $37^{\circ} \mathrm{C}$. After incubation, the cells were washed with PBS and collected to a multiwell UniFilter using an automatic multiple cell harvester (Filtermate 196, Packard). Liquid scintillation fluid (50 $\mu 1$ ) (Microscint-O, Packard) was added to each well and the radioactivity was recorded using a microplate scintillation counter (Packard Topcount).

$R N A$ extraction and RT-PCR. The total cellular mRNA from LNCaP cells was isolated using the TRIzol reagent (Invitrogen, $\mathrm{CA}$ ) according to the manufacturer's instructions. Real-time quantitative RT-PCR was performed on the ABI Prism 7700 Sequence Detection System using TaqMan Universal PCR Master Mix (Applied Biosystems; Foster City, CA). The PCR primers and TaqMan probes for $A R$ and $B$-actin were obtained from Applied Biosystems. The PCR conditions were as follows: an initial incubation at $50^{\circ} \mathrm{C}$ for $2 \mathrm{~min}$, then a denaturation at $95^{\circ} \mathrm{C}$ for $10 \mathrm{~min}$, followed by 40 cycles of $95^{\circ} \mathrm{C}$ for $15 \mathrm{sec}$ and $60^{\circ} \mathrm{C}$ for $1 \mathrm{~min}$. The relative quantification of gene expression was carried out using the comparative $\mathrm{C}_{\mathrm{T}}$ method.

PSA ELISA. Cells were seeded at $2 \times 10^{4}$ cells/well in 24-well plates. After $72 \mathrm{~h}$ the medium was changed to an androgenfree medium for an additional $24 \mathrm{~h}$ to deplete endogenous steroids prior to assay. The cells were then treated with etoposide at different concentrations, with or without $1 \mathrm{nM}$ $\mathrm{R} 1881$, for $24 \mathrm{~h}$. The supernatants were collected and subjected to low-speed centrifugation to remove cell debris. The PSA protein level in the culture medium was determined using the CytElisa $^{\mathrm{TM}}$ Human PSA kit and normalized according to the total number of cells.

Subcellular fractionation. Cells were lysed in hypotonic buffer (10 mM Hepes, pH 7.5) and harvested in MDH buffer ( $3 \mathrm{mM}$ $\mathrm{MgCl}_{2}, 1 \mathrm{mM}$ dithiothreitol, $25 \mathrm{mM}$ Hepes, $\mathrm{pH}$ 7.5). After homogenization, the supernatant was stored as for cytosolic proteins and nuclear proteins were extracted from the pellets with MDHK buffer ( $3 \mathrm{mM} \mathrm{MgCl}_{2}, 1 \mathrm{mM}$ dithiothreitol, $100 \mathrm{mM} \mathrm{KCl,} 25 \mathrm{mM}$ Hepes, pH 7.5), followed by HDK (25 mM Hepes, $1 \mathrm{mM}$ dithiothreitol, $400 \mathrm{mM} \mathrm{KCl}$ ). Cytosolic and nuclear extracts were subsequently analyzed by Western blot analysis, as described (9).

Immunoprecipitation and Western blot analysis. After treatment, the cells used for immunoprecipitation were lysed on ice for $30 \mathrm{~min}$ in lysis buffer $(20 \mathrm{mM}$ Tris-HCl, $1 \%$ NP-40, $3 \mathrm{mM}$ EDTA, $3 \mathrm{mM}$ EGTA, $5 \mathrm{mM}$ ß-glycerophosphate, $100 \mu \mathrm{M} \mathrm{Na} V_{3} \mathrm{O}_{4}, 250 \mathrm{mM} \mathrm{NaCl}$ and protease inhibitor cocktail). Protein concentrations were determined using the Bio-Rad protein assay (Richmond, CA). The extracts (200 $\mu \mathrm{g}$ of protein) were incubated with $2 \mu \mathrm{g}$ of antibody for $2 \mathrm{~h}$ at $4^{\circ} \mathrm{C}$ and subsequently with $25 \mu \mathrm{l}$ of a $50 \%$ slurry of protein $\mathrm{A}$ sepharose for an additional $2 \mathrm{~h}$ at $4^{\circ} \mathrm{C}$. The beads were collected by centrifugation, washed three times and boiled for $5 \mathrm{~min}$ in $2 \mathrm{X}$ SDS-PAGE sample buffer. Immunoprecipitates or cell lysates were separated by SDS-PAGE and transferred to nitrocellulose membranes. Western blot analysis was performed, as described previously (10).

Confocal microscopy and imaging analysis. Cells were cultured in 8-well polylysine-coated chamber slides and treated with etoposide in phenol red-free RPMI-1640 containing 5\% CSS, with or without $1 \mathrm{nM}$ R1881, for the time indicated. The cells were washed once with PBS and fixed for 5 min in ice-cold methanol. Non-specific binding sites were blocked with PBS containing 5\% normal goat serum. Cells were incubated with anti-AR mouse monoclonal antibody at room temperature for $1 \mathrm{~h}$. After extensive washes in PBS, the slides were then stained with 488 Alexa conjugated goat anti-mouse $\mathrm{IgG}$ (Molecular Probe) for $1 \mathrm{~h}$ at room temperature in the dark and nuclei were counterstained with DAPI. After extensive washes, the slides were mounted in a drop of antifade mounting medium (Vectashield) to reduce photobleaching and examined using a confocal laser scanning microscope (Leica, Germany).

Competitive binding assay for AR. Cells were plated at $2 \times 10^{5}$ in polylysine-coated dishes and grown to subconfluence in $5 \%$ CSS medium. After starvation in basal medium for $24 \mathrm{~h}$, the cells were treated with $2 \mathrm{ml}$ of serum-free RPMI-1640 containing $10 \mathrm{nM}\left[{ }^{3} \mathrm{H}\right] \mathrm{R} 1881$ and $1 \mu \mathrm{M}$ triamcinolone acetonide to saturate progesterone and glucocorticoid receptors, in the presence or absence of 200 -fold excess of cold competitors (R1881, CPA) or the indicated concentrations of etoposide and 17AAG. After additional incubation at $37^{\circ} \mathrm{C}$ for $2 \mathrm{~h}$, each sample was collected using a sampling harvester and unbound ligand was removed by extensive washes. Fiber filters that contained bound ligand were transferred to counting vials containing $5 \mathrm{ml}$ of liquid scintillation fluid and counted with a multipurpose scintillation counter (Aloka LSC-5700).

\section{Results}

Etoposide inhibits the cell growth and DNA synthesis. We first examined the cell viability by XTT assay to evaluate the effect of etoposide on prostate cancer. As shown in Fig. 1A, inhibition of cell growth occurred initially at $\sim 0.5 \mu \mathrm{M}$, increased as the dose was increased and maximal inhibition was achieved at $40 \mu \mathrm{M}$ in LNCaP cells after treatment with etoposide for $48 \mathrm{~h}$. Androgen-dependent LNCaP cells were 
A

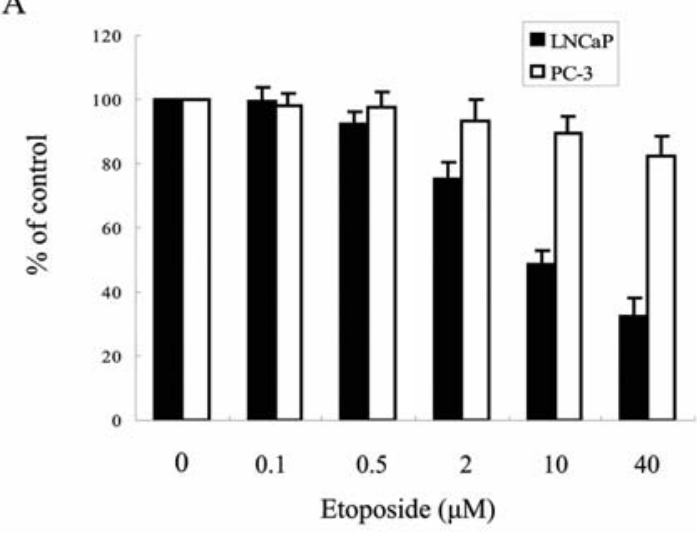

B

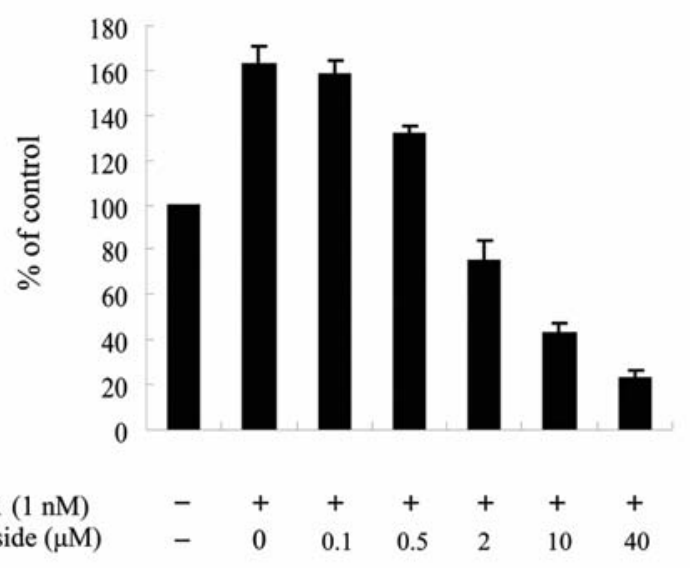

$\mathrm{C}$

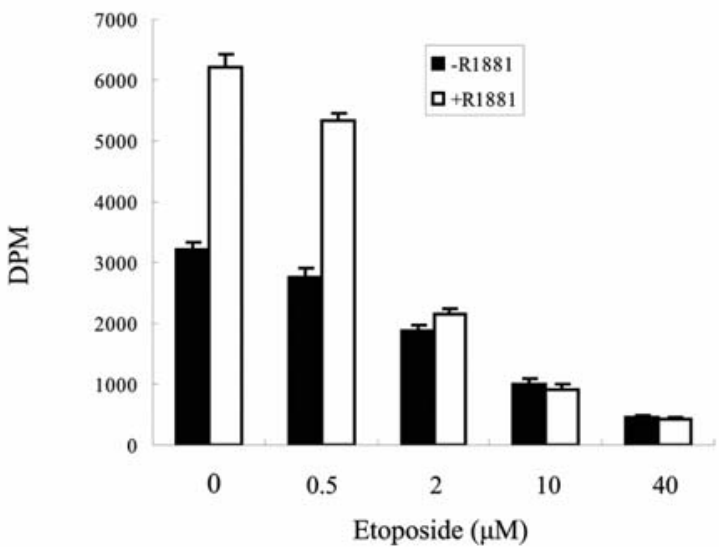

Figure 1. Etoposide inhibits cell growth and DNA synthesis in prostate carcinoma cell lines. (A) LNCaP and PC-3 cells grown in normal 5\% FBS medium were treated with vehicle (DMSO) or various concentrations of etoposide $(0.1-40 \mu \mathrm{M})$ for $48 \mathrm{~h}$. Cell viability was determined by XTT assay. (B) LNCaP cells grown in androgen-free 5\% CSS medium were treated with vehicle or various concentrations of etoposide $(0.1-40 \mu \mathrm{M})$ in the presence or absence of $1 \mathrm{nM} \mathrm{R} 1881$ for $48 \mathrm{~h}$. Cell viability was determined by XTT assay. (C) LNCaP cells grown in 5\% FBS or CSS medium in the presence or absence of $1 \mathrm{nM} \mathrm{R} 1881$ were treated with vehicle or various concentrations of etoposide $(0.1-40 \mu \mathrm{M})$ for $24 \mathrm{~h}$. The cells were pulsed with $1 \mu \mathrm{Ci} /$ well of $\left[{ }^{3} \mathrm{H}\right]$ thymidine, followed by incubation for an additional $4 \mathrm{~h}$ and then the radioactivity was counted using a microplate scintillation counter. The values are expressed as percentage of control and presented in mean $\pm \mathrm{SD}$ of at least four individual samples. much more sensitive to etoposide, we therefore used this cell model for further study.

The ability of etoposide to inhibit proliferation stimulated by androgen in LNCaP cells was also examined and results are presented in Fig. 1B. Androgen-enhanced LNCaP cell proliferation in medium with $1 \mathrm{nM}$ R1881 is $~ 1.7$ times greater than that of vehicle-treated cells in androgen-free medium, which confirms the cell-growth response to androgen stimulation. Similarly, this androgen-stimulated proliferation was inhibited markedly by etoposide in a dose-dependent manner.

To assess the effect of etoposide on DNA synthesis, the cells were pulse-labeled with $\left[{ }^{3} \mathrm{H}\right]$ thymidine incorporation under the same conditions as described above. Androgen caused a striking increase in $\left[{ }^{3} \mathrm{H}\right]$ thymidine uptake after the cells were exposed to $1 \mathrm{nM}$ R1881 (Fig. 1C). However, the androgen-stimulated DNA synthesis was suppressed appreciably by etoposide in a dose-dependent manner. These data correspond with results from the cell proliferation assay, which indicates that etoposide strongly suppresses cell growth and DNA synthesis in prostate cancer cells.

Etoposide down-regulates AR expression and blocks $A R$ nuclear translocation. To determine the effect of etoposide on the expression of AR mRNA, the steady-state level of AR mRNA was analyzed by real-time reverse transcriptionPCR after treatment with etoposide at different concentrations. As shown in Fig. 2A, the reduction of AR mRNA expression occurred initially at $0.5 \mu \mathrm{M}$, increased as the dose was increased and the amount of inhibition rose to $85 \%$ at $40 \mu \mathrm{M}$ by $24 \mathrm{~h}$ after exposure of LNCaP cells to etoposide. This finding suggests that the decrease in AR mRNA level by etoposide is attributable to the blocking of AR transcription.

To determine whether etoposide affects AR protein expression, Western blot analysis was performed after the cells were exposed to etoposide at different concentrations in $5 \%$ FBS medium. As shown in Fig. 2B, treatment of the cells with etoposide at low concentration resulted in a modest reduction of AR expression. As the dose was increased over a period of $48 \mathrm{~h}, \mathrm{AR}$ expression was eliminated almost completely at concentrations higher than $40 \mu \mathrm{M}$. These findings indicate that etoposide not only suppresses AR mRNA expression, but also represses AR protein expression.

We used confocal microscopy to determine whether etoposide induces AR translocation. As shown in Fig. 2C, without androgen stimulation, endogenous AR was distributed diffusely in the cytoplasm and nucleus of LNCaP cells. The addition of $1 \mathrm{nM}$ R1881 resulted in rapid translocation of most of the cytoplasmic AR into the nucleus. Nuclear migration of AR was evident shortly after androgen treatment and the receptor became almost completely nuclear within $60 \mathrm{~min}$ (data not shown). All cells treated with R1881 for $24 \mathrm{~h}$ showed strong positive nuclear staining. Intriguingly, etoposide cocultured with R1881 for $24 \mathrm{~h}$ notably decreased the nuclear localization of AR. However, this reduction of nuclear AR staining did not coincide with nuclear condensation and fragmentation by DAPI-staining nuclei. This finding suggests that the loss of AR activity is unlikely a consequence of etoposide-mediated apoptosis. 
$\mathbf{A}$

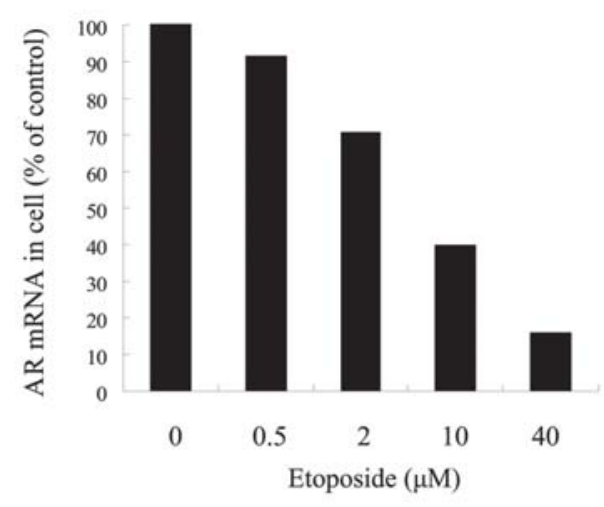

C

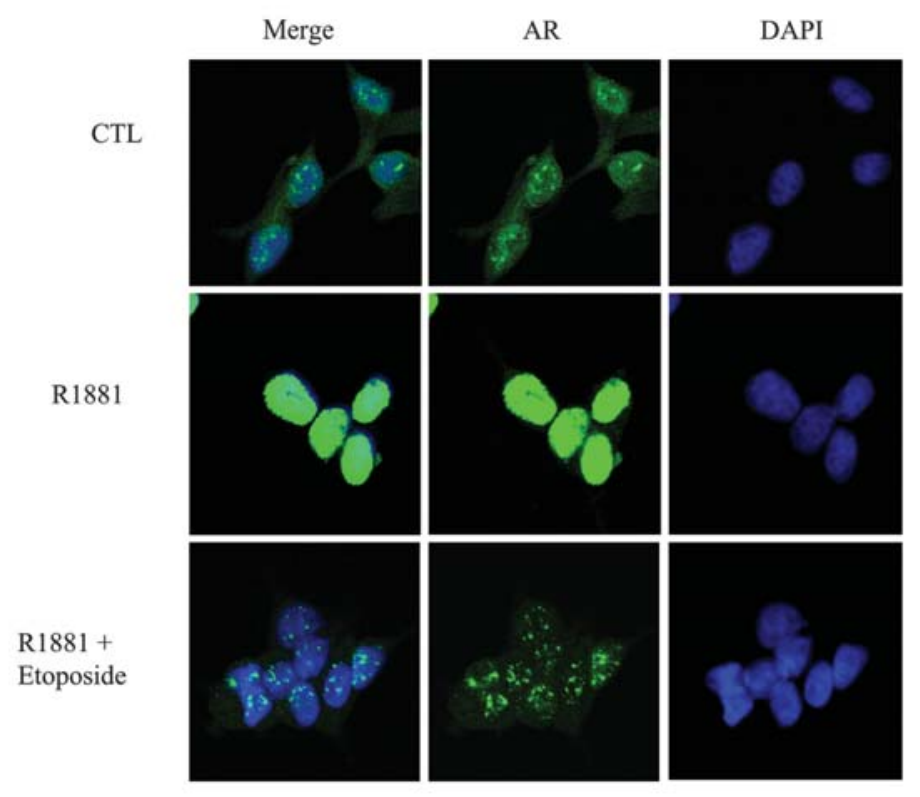

D

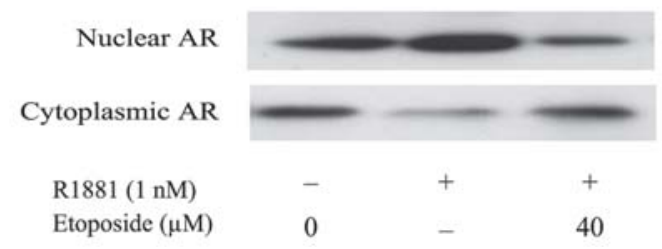

Figure 2. Etoposide down-regulates AR expression and blocks AR nuclear translocation. (A) AR mRNA expression in LNCaP cells was determined by quantitative real-time RT-PCR after exposure of the cells for $24 \mathrm{~h}$ to various concentrations of etoposide. (B) The cellular AR and Hsp90 protein levels were determined by Western blot analysis after exposure of the cells for $48 \mathrm{~h}$ to various concentrations of etoposide in 5\% FBS medium. (C) LNCaP cells grown on chamber slides were treated with or without $40 \mu \mathrm{M}$ etoposide 30 min prior to vehicle or $1 \mathrm{nM} \mathrm{R} 1881$ treatment. After incubation for $24 \mathrm{~h}$, the cells were fixed with cold methanol, followed by staining with an anti-AR antibody and then examined by confocal microscopy. (D) Subcellular localization of AR in LNCaP cells was determined by Western blot analysis after exposure of the cells to $40 \mu \mathrm{M}$ etoposide in medium containing 5\% CSS 30 min prior to vehicle or $1 \mathrm{nM}$ R1881 treatment. The cytosolic and nuclear protein fractions were extracted as described in Materials and methods. B-actin was probed as an internal control.

Next, we prepared cytosolic and nuclear fractions for Western blot analysis after treatment with etoposide $30 \mathrm{~min}$ prior to the addition of $1 \mathrm{nM} \mathrm{R} 1881$. The androgen-stimulated AR expression in the nuclear fraction was reduced significantly after treatment with etoposide. By contrast, AR expression in the cytoplasm was simultaneously enhanced after treatment (Fig. 2D). These findings suggest that etoposide might suppress AR transactivation via the interruption of AR nuclear translocation.
Etoposide disrupts AR-heat shock protein 90 association and blocks androgen binding to AR. AR is known to form a heteromeric complex with two molecules of Hsp90, which participate in regulating the protein stability of ligand-unbound AR. To determine the efficacy of etoposide on the reduction of AR and interaction between AR and hsp90, Hsp90-AR coimmunoprecipitation assay was performed. In response to etoposide treatment, the amount of Hsp90 associated with AR in the complex reduced rapidly and was nearly undetectable at 
A

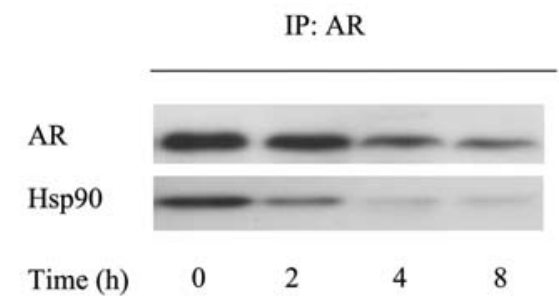

B

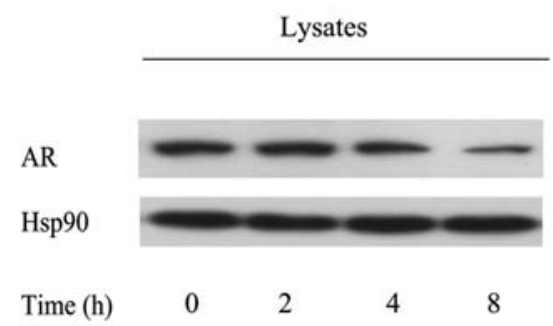

C

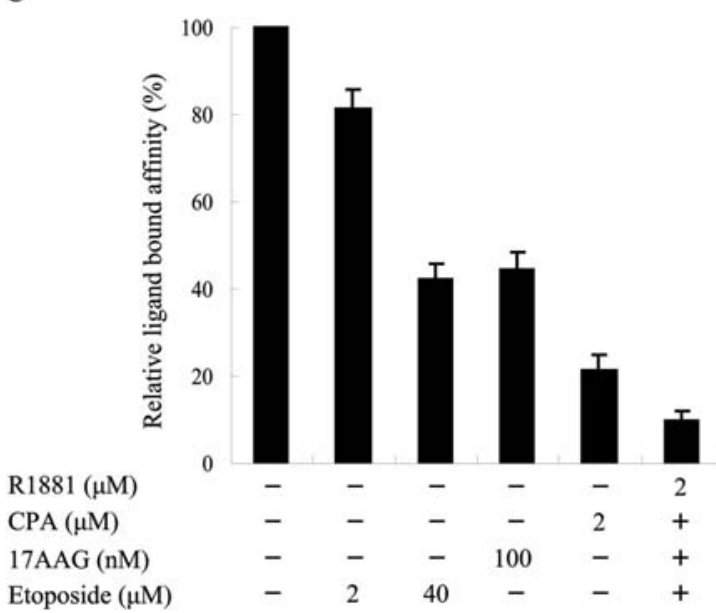

Figure 3. Etoposide disrupts AR-Hsp90 association and blocks androgen binding to AR. (A) The interaction between Hsp90 and AR in response to etoposide treatment for the indicated doses was analyzed by immunoprecipitation with anti-AR antibody, followed by Western blot analysis with anti-AR or anti-Hsp90 antibodies. (B) Cell lysate supernatants used in the immunoprecipitation was analyzed by Western blot analysis. B-actin was probed as an internal control. (C) LNCaP cells grown to subconfluence were treated in serum-free medium containing $10 \mathrm{nM}\left[{ }^{3} \mathrm{H}\right] \mathrm{R} 1881$ in the presence or absence of 200-fold excess of cold competitor (R1881, CPA) or the indicated concentrations of etoposide and 17AAG for $2 \mathrm{~h}$. The cells were harvested on the filters and the radioactivity was determined with a scintillation counter. $\left[{ }^{3} \mathrm{H}\right] \mathrm{R} 1881$-binding without competition was set as $100 \%$ and data are presented as mean \pm SD from three individual samples.

$4 \mathrm{~h}$, while the amount of AR bound to Hsp90 declined at much slower rate (Fig. 3A). In addition, analysis of cell lysate supernatants used in the immunoprecipitation showed that the same level of Hsp90 was present in all samples (Fig. 3B). These data indicate that etoposide dissociates Hsp90 from AR complex.

To determine whether etoposide has a specific affinity to $\mathrm{AR}$ in LNCaP cells, the ability of etoposide to block the binding of $\left[{ }^{3} \mathrm{H}\right] \mathrm{R} 1881$ to AR was examined by competitive
$\mathbf{A}$

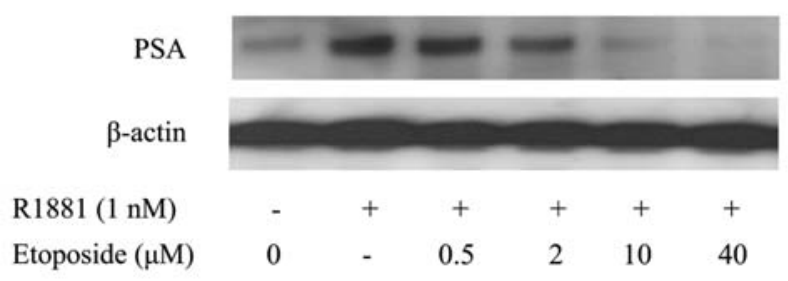

B

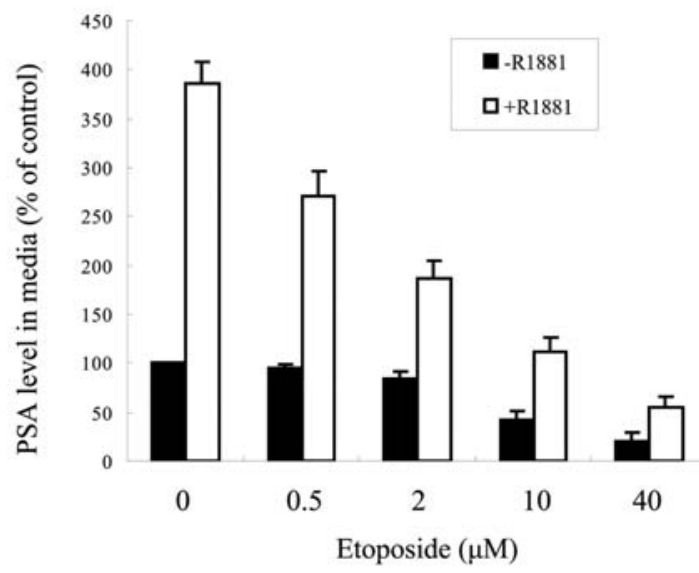

Figure 4. Etoposide inhibits the intracellular and secreted PSA level. (A) The intracellular PSA protein level was determined by Western blot analysis after exposure of the cells for $24 \mathrm{~h}$ to various concentrations of etoposide in medium, with or without $1 \mathrm{nM} \mathrm{R} 1881$. B-actin was probed as an internal control. (B) The secreted PSA in medium was determined using an ELISA kit after exposure of the cells for $24 \mathrm{~h}$ to various concentrations of etoposide in medium, with or without $1 \mathrm{nM}$ R1881.

radioligand-binding assay. LNCaP cells were incubated in steroid-free media containing $10 \mathrm{nM}\left[{ }^{3} \mathrm{H}\right] \mathrm{R} 1881$ with various concentrations of etoposide and reference drugs. As shown in Fig. 3C, unlabeled R1881 binds to LNCaP AR at almost 90\%, while the well-known antagonist CPA displaced $80 \%$ of $\left[{ }^{3} \mathrm{H}\right]$ R1881 at $>200$-fold concentrations of labeling $\left[{ }^{3} \mathrm{H}\right] \mathrm{R} 1881$. Similar to Hsp90 inhibitor 17AAG, etoposide is also able to compete with labeled R1881 for binding to the AR and exhibits a similar binding affinity for the AR.

Etoposide inhibits secreted and intracellular level of PSA. To verify the effect of etoposide on the androgen-regulated expression of PSA, the intracellular PSA protein expression was analyzed by Western blot analysis (see Fig. 4A). Control cells cultured in androgen-free medium constitutively expressed a significantly low level of PSA protein. With synthetic androgen R1881, the intracellular PSA level in these cells increased dramatically. This androgen-regulated PSA protein level was suppressed markedly by coculture with etoposide for $24 \mathrm{~h}$.

Next, the secreted PSA stimulated by androgen was determined using an ELISA kit. In agreement with the results above, androgen pronouncedly enhanced the amount of PSA 
protein secreted into media. Similarly, etoposide reduced markedly the amount of secreted PSA stimulated by androgen after coculture with androgen (Fig. 4B). These findings are consistent with our hypothesis that the cell growth inhibited by etoposide is possibly involved in impairing the AR function by blocking AR signaling transduction.

\section{Discussion}

Prostate cancer remains the most commonly diagnosed malignancy and is second only to lung cancer as the leading cause of cancer-related deaths in American men (11). Advanced prostate cancer is often treated with chemotherapy and most of these drugs exert their function by generating genotoxic stress. In the present study, we use an in vitro model to explore the molecular mechanism of etoposide-induced growth inhibition in prostate cancer cells. The major and novel finding of the present study can be summarized as follows: i) etoposide strikingly inhibited androgen/AR-mediated cell growth and androgen-stimulated DNA synthesis, ii) etoposide down-regulated the expression of AR and PSA, iii) etoposide blocked AR binding to androgens, iv) etoposide disrupted AR-Hsp90 association and v) etoposide attenuated AR nuclear translocation in prostate cancer cells.

Structurally, AR has a highly-conserved DNA-binding domain (DBD) that consists of two zinc fingers each, which are expressed by separate exons. One zinc finger establishes the receptor-DNA contact by binding a specific hormone response element (HRE), while the other is involved in receptor dimerization (12). Our results of competitive binding assay show that etoposide is able to compete with labeled R1881 for binding to the AR. This ability of etoposide to block AR binding to androgen is similar to Hsp90 inhibitor 17AAG. However, etoposide is unlikely to act as a pure antagonist to block AR binding to androgen via steric hindrance since it exhibits less than obvious structure similarity to the endogenous AR ligand, R1881.

Members of the $90-\mathrm{kDa}$ heat shock protein family are known to bind and stabilize intermediates in a wide variety of cell signaling pathways and contribute to their dysregulation in cancer (13). As the AR is an Hsp90 chaperone, it is possible that loss of AR activity and loss of protein expression in response to etoposide could be related to an etoposide-induced inhibition of Hsp90 in LNCaP cells. The present study from immunoprecipitation indicates that etoposide induces dissociation of the Hsp90-AR complex. These findings suggest that blocking of AR binding to androgen by etoposide is due to disrupting the association of Hsp90-AR complex rather than enhancing steric hindrance.

It is usually assumed that unbound AR localizes predominantly in the cytoplasm, where it is sequestered as a multiprotein complex with heat shock proteins. Upon binding with androgen, AR dissociates from the multiprotein complex and translocates into the nucleus, resulting in the stimulation or inhibition of AR-mediated gene expression (14). Our present results show that androgen-induced AR translocation can be blocked by etoposide. This AR nuclear translocation is associated with the dissociation of AR and Hsp90. These data suggest that etoposide-mediated inhibition of AR nuclear translocation is specific and involves a novel mechanism correlating with the dissociation of AR and Hsp90.
PSA is an androgen-regulated serine protease produced by both prostate epithelial cells and prostate cancer and is the most commonly used serum marker for cancer (15). The use of PSA allows the detection of cancer at in its early stages. It also serves as a marker for monitoring a tumor's growth or shrinkage under various treatment regimens for prostate cancer screening and assessment. The present study shows that etoposide is able to down-regulate the intracellular and secreted PSA protein level in LNCaP cells via a mechanism involving disruption of the androgen signal transduction pathway. The down-regulation of PSA by etoposide has significant clinical implication. In patients treated with etoposide, the monitoring of PSA in the circulation could potentially be evaluated as a barometer to gauge the efficacy of intervention.

Taken together, the data presented in this in vitro study provide important insights into this AR-targeted therapeutic strategy and form a strong basis for future prostate cancer drug discovery.

\section{References}

1. Chang CS, Kokontis J and Liao ST: Molecular cloning of human and rat complementary DNA encoding androgen receptors. Science 240: 324-326, 1988.

2. Rahman M, Miyamoto $\mathrm{H}$ and Chang CS: Androgen receptor coregulators in prostate cancer: mechanisms and clinical implications. Clin Cancer Res 10: 2208-2219, 2004.

3. Gobinet J, Poujol N and Sultan C: Molecular action of androgens. Mol Cell Endocrinol 198: 15-24, 2002.

4. Gelmann EP: Molecular biology of the androgen receptor. J Clin Oncol 20: 3001-3015, 2002.

5. Dixon SC, Knopf KB and Figg WD: The control of prostatespecific antigen expression and gene regulation by pharmacological agents. Pharmacol Rev 53: 73-91, 2001.

6. Mizumoto K, Rothman RJ and Farber JL: Programmed cell death (apoptosis) of mouse fibroblasts is induced by the topoisomerase II inhibitor etoposide. Mol Pharmacol 46: 890-895, 1994.

7. Burden AD and Osheroff N: Mechanism of action of eukaryotic topoisomerase II and drugs targeted to the enzyme. Biochim Biophys Acta 1400: 139-154, 1998.

8. Karpinich NO, Tafani M, Rothman RJ, Russo MA and Farber JL: The course of etoposide-induced apoptosis from damage to DNA and 553 activation to mitochondrial release of cytochrome c. J Biol Chem 277: 16547-16552, 2002.

9. Liu S and Yamauchi H: Hinokitiol, a metal chelator derived from natural plants, suppresses cell growth and disrupts androgen receptor signaling in prostate carcinoma cell lines. Biochem Biophys Res Commun 351: 26-32, 2006.

10. Liu S, Mizu H and Yamauchi H: Molecular response to phototoxic stress of UVB-irradiated ketoprofen through arresting cell cycle in $\mathrm{G} 2 / \mathrm{M}$ phase and inducing apoptosis. Biochem Biophys Res Commun 364: 650-655, 2007.

11. Retter AS, Gulley JL and Dahut WL: Novel therapeutic strategies in prostate cancer. Cancer Bio1 Ther 3: 371-376, 2004.

12. Wickert L and Selbig J: Structural analysis of the DNA-binding domain of alternatively spliced steroid receptors. J Endocrinol 173: 429-436, 2002.

13. Gray PJ Jr, Stevenson MA and Calderwood SK: Targeting Cdc37 inhibits multiple signaling pathways and induces growth arrest in prostate cancer cells. Cancer Res 67: 11942-11950, 2007.

14. Roy AK, Tyagi RK, Song CS, Lavrovski Y, Ahn SC and Chatterjee B: Androgen receptor: structural domains and functional dynamics after ligand-receptor interaction. Ann NY Acad Sci 949: 44-57, 2001.

15. Balk SP, Ko YL and Bubley GJ: Biology of prostate-specific antigen. J Clin Oncol 21: 383-391, 2003. 